ORIGINAL ARTICLE

\section{Natural History and Outcome in Systemic AA Amyloidosis}

\author{
Helen J. Lachmann, M.D., Hugh J.B. Goodman, M.B., B.S., Janet A. Gilbertson, \\ J. Ruth Gallimore, B.Sc., Caroline A. Sabin, Ph.D., Julian D. Gillmore, Ph.D., \\ and Philip N. Hawkins, Ph.D., F. Med.Sci.
}

\section{A B STRACT}

\section{BACKGROUN D}

Deposition of amyloid fibrils derived from circulating acute-phase reactant serum amyloid A protein (SAA) causes systemic AA amyloidosis, a serious complication of many chronic inflammatory disorders. Little is known about the natural history of AA amyloidosis or its response to treatment.

\section{METHODS}

We evaluated clinical features, organ function, and survival among 374 patients with AA amyloidosis who were followed for a median of 86 months. The SAA concentration was measured serially, and the amyloid burden was estimated with the use of whole-body serum amyloid P component scintigraphy. Therapy for inflammatory diseases was administered to suppress the production of SAA.

\section{RESULTS}

Median survival after diagnosis was 133 months; renal dysfunction was the predominant disease manifestation. Mortality, amyloid burden, and renal prognosis all significantly correlated with the SAA concentration during follow-up. The risk of death was 17.7 times as high among patients with SAA concentrations in the highest eighth, or octile, ( $\geq 155 \mathrm{mg}$ per liter) as among those with concentrations in the lowest octile ( $<4 \mathrm{mg}$ per liter); and the risk of death was four times as high in the next-to-lowest octile (4 to $9 \mathrm{mg}$ per liter). The median SAA concentration during follow-up was $6 \mathrm{mg}$ per liter in patients in whom renal function improved and $28 \mathrm{mg}$ per liter in those in whom it deteriorated $(\mathrm{P}<0.001)$. Amyloid deposits regressed in $60 \%$ of patients who had a median SAA concentration of less than $10 \mathrm{mg}$ per liter, and survival among these patients was superior to survival among those in whom amyloid deposits did not regress $(\mathrm{P}=0.04)$.

\section{CONCLUSIONS}

The effects of renal dysfunction dominate the course of AA amyloidosis, which is associated with a relatively favorable outcome in patients with SAA concentrations that remain in the low-normal range ( $<4 \mathrm{mg}$ per liter).
From the National Amyloidosis Centre and Centre for Amyloidosis and Acute Phase Proteins, Department of Medicine (H.J.L., H.J.B.G., J.A.G., J.R.G., J.D.G., P.N.H.), and the Department of Primary Care and Population Sciences (C.A.S.), Royal Free and University College Medical School, London.

N EnglJ Med 2007;356:2361-71. Copyright (C) 2007 Massachusetts Medical Society. 
EACTIVE SYSTEMIC AA AMYLOIDOSIS CAN complicate chronic inflammatory disorders that are associated with a sustained acutephase response. AA amyloid fibrils are derived from the acute-phase reactant serum amyloid A protein (SAA) protein through a process of cleavage, misfolding, and aggregation into a highly ordered abnormal $\beta$-sheet conformation. ${ }^{1}$ Amyloid fibrils associate with other moieties, including glycosaminoglycans and serum amyloid P component (SAP), forming deposits that disrupt the structure and function of tissues and organs. ${ }^{2}$ SAA is an apolipoprotein constituent of high-density lipoprotein ${ }^{3}$ that is synthesized by hepatocytes under the transcriptional regulation of proinflammatory cytokines. ${ }^{4}$ The median plasma concentration of SAA in healthy persons is $3 \mathrm{mg}$ per liter, but the concentration can increase to more than $2000 \mathrm{mg}$ per liter during the acute-phase response. ${ }^{5}$ Sustained overproduction of SAA is a prerequisite for the development of AA amyloidosis, although for reasons that are not known, amyloidosis occurs only in a small proportion of patients with chronic inflammatory disorders. ${ }^{6,7}$

Few systematic clinical studies of AA amyloidosis have been reported, and recent data on its clinical features, natural history, and long-term outcome are scanty. We report the clinical features and course in 374 patients with AA amyloidosis who were followed at a single national center during a period of 15 years. In addition to conventional clinical follow-up assessment, the amyloid burden was estimated annually with the use of SAP scintigraphy, and the plasma concentration of the AA amyloid precursor protein was monitored by monthly measurement of SAA.

\section{METHODS}

\section{PATIENTS}

We included in this study all 374 patients with systemic AA amyloidosis who were referred to the U.K. National Amyloidosis Centre during a period of 15 years, to August 2005. The diagnosis of AA amyloidosis was confirmed in 320 patients by immunohistochemical testing and in 54 patients by noninvasive means. Inclusion criteria were amyloid deposition on SAP scintigraphy; evidence of an overt chronic inflammatory disease, no mutations in the genes encoding transthyretin, the fibrinogen A $\alpha$-chain, apolipoprotein A-I, apolipoprotein A-II, and lysozyme (to rule out hereditary forms of amyloidosis ${ }^{8,9}$ ); negative serum free light- chain assay; negative monoclonal immunoglobulin screening, including the use of serum and urine immunofixation (to rule out monoclonal lightchain [AL] amyloidosis $\left.{ }^{10,11}\right)$; and the absence of neuropathy and of cardiac amyloidosis, both of which are uncommon in the AA type of amyloidosis. A biopsy was performed if any of these criteria were not met. The study was approved by the ethics committee of the Royal Free Hospital, and all patients provided written informed consent.

\section{CONGO RED STAINING AND}

\section{IMMUNOHISTOCHEMICAL TESTING}

The Congo red method ${ }^{12}$ was used to detect amyloid in tissue sections. Amyloid was identified as the AA type on immunohistochemical testing with the use of monoclonal antibodies specific to SAA (Euro-Diagnostica). ${ }^{13}$

\section{CLINICAL ASSESSMENT}

Patients underwent an initial clinical assessment and annual review at our center. Blood samples were scheduled to be obtained monthly to determine the SAA concentration, and a mean of 10.6 samples per patient per year were obtained. Quantitative estimation of the distribution and extent of visceral amyloid deposits was performed with the use of whole-body ${ }^{123}$ I-labeled SAP scintigraphy. ${ }^{14}$ Blinded assessments of amyloid deposits were performed at baseline and annually by an investigator with expertise in the interpretation of SAP scans. The whole-body amyloid burden was classified as 0 when there was no abnormal localization of the tracer; as small when uptake in one or more organs was discernible but the intensity of the blood-pool background signal remained normal; as moderate when abnormal uptake in one or more organs was sufficiently intense for the bloodpool background signal to be partially lost when the gray scale was normalized to encompass the target-organ signal; and as large when the bloodpool background was lost with adjustment of the gray scale to encompass the target-organ uptake.

Regression of amyloid was defined as a reduction in tracer uptake in affected organs or an increase in the blood-pool background signal, or both; an accumulation of amyloid was defined as an increase in tracer uptake in affected organs, an abnormal tracer uptake in a previously unaffected organ, or a decrease in the blood-pool background signal; and a stable amyloid burden was defined as unchanged tracer localization. ${ }^{15,16}$ Clinically important organ involvement and changes in or- 
gan function were defined according to international consensus criteria. ${ }^{17}$ Deteriorating kidney function was categorized as either the onset of end-stage renal failure, defined by a requirement for long-term dialysis, or as an increase of $25 \%$ or more in the serum creatinine concentration or a decrease of $25 \%$ or more in creatinine clearance measured by 24-hour urine collection. In patients in whom the serum creatinine concentration or creatinine clearance did not deteriorate by $25 \%$ or more, renal function was deemed to have deteriorated if urinary protein excretion had increased by $50 \%$ or more and by more than $1 \mathrm{~g}$ per day ( 24 hours). Renal function was categorized as improved if the serum creatinine concentration or creatinine clearance improved by $25 \%$ or more, or if these values did not worsen if 24-hour urinary protein excretion decreased by more than $50 \%$ and by more than $0.5 \mathrm{~g}$. Patients whose condition met none of these criteria were classified as having stable kidney function. SAA was assayed with the use of latex-enhanced immunonephelometry (BN II analyzer, Dade Behring) with the use of the World Health Organization's International Reference Standard. $5,18,19$

\section{TREATMENT}

Treatment was undertaken with the objective of suppressing underlying inflammatory disease (Table 1) and reducing the SAA concentration as

\begin{tabular}{|c|c|c|}
\hline Underlying Disorder & No. of Patients (\%) & Examples of Treatment \\
\hline Chronic inflammatory arthritis & $224(60)$ & $\begin{array}{l}\text { Immunosuppressive agents: chlorambucil (Leukeran, GlaxoSmithKline) } \\
\text { or cyclophosphamide (Cytoxan, Bristol-Myers Squibb); methotrexate } \\
\text { (Rheumatrex, Wyeth-Ayerst). Biologic agents: anti-TNF therapies and } \\
\text { interleukin-l-receptor antagonists }\end{array}$ \\
\hline Rheumatoid arthritis & $123(33)$ & \\
\hline Juvenile idiopathic arthritis & $64(17)$ & \\
\hline $\begin{array}{l}\text { Other chronic inflammatory } \\
\text { arthritides }\end{array}$ & $37(10)$ & \\
\hline Chronic sepsis & $56(15)$ & \\
\hline Bronchiectasis & $20(5)$ & Surgery, physiotherapy, and antibiotics \\
\hline Injection-drug abuse & $13(4)$ & Drug rehabilitation programs and antibiotics \\
\hline $\begin{array}{l}\text { Complications of paraplegia (infected } \\
\text { pressure sores, urinary infection) }\end{array}$ & $8(2)$ & $\begin{array}{l}\text { Physiotherapy, treatment of pressure ulcers, procedures for urinary drain- } \\
\text { age, and antibiotics }\end{array}$ \\
\hline Other & $7(2)$ & Surgery and antibiotics \\
\hline Osteomyelitis & $5(1)$ & Surgery and antibiotics \\
\hline Tuberculosis & $3(1)$ & Antituberculous therapy \\
\hline Periodic fever syndromes & $32(9)$ & \\
\hline Familial Mediterranean fever & $20(5)$ & Colchicine \\
\hline $\begin{array}{l}\text { TNF-receptor-associated periodic fever } \\
\text { syndrome }\end{array}$ & $6(2)$ & Anti-TNF therapy \\
\hline Muckle-Wells syndrome & $4(1)$ & Interleukin-1-receptor antagonist \\
\hline Hyper-IgD and periodic fever syndrome & $2(<1)$ & Anti-TNF therapies and interleukin-1-receptor antagonist \\
\hline Crohn's disease & $17(5)$ & Anti-TNF therapies, surgical resection, immunosuppressive agents \\
\hline Miscellaneous & $22(6)$ & \\
\hline Castleman's disease & $7(2)$ & Surgical excision \\
\hline Neoplasia (lymphoma, mesothelioma) & $4(1)$ & Chemotherapy \\
\hline Vasculitis & $4(1)$ & Immunosuppressive agents \\
\hline Other & $7(<2)$ & \\
\hline Unknown & $23(6)$ & \\
\hline
\end{tabular}

* Percentages may not sum to 100 because of rounding. A patient may have had more than one underlying disease. TNF denotes tumor necrosis factor. 
much as possible. Patients also received supportive care, including, when required, renal-replacement therapy.

\section{STATISTICAL ANALYSIS}

Survival and time from the diagnosis of amyloidosis to end-stage renal failure (dependence on dialysis) were estimated in Kaplan-Meier analyses. Changes in renal function were analyzed in the subgroup of 257 patients who had a creatinine clearance greater than $20 \mathrm{ml}$ per minute $(0.3 \mathrm{ml}$ per second) at baseline - that is, those in whom progression to end-stage renal failure was not deemed to be inevitable. Relationships of a variety of factors with survival and with the development of end-stage renal failure were examined with the use of Cox regression analysis. Potential covariates were categorized as factors that were fixed at the baseline assessment (age, sex, race or ethnic group, calendar year when amyloidosis was diagnosed, initial amyloid burden and renal function, evidence of hepatic amyloid, underlying disease, and duration of inflammatory disease before diagnosis) or as factors that could vary between annual followup assessments. Race or ethnic group was selfreported. Factors that could vary (changes in amyloid burden, serum albumin concentration, median SAA concentration, creatinine concentration, creatinine clearance, proteinuria, and the development of end-stage renal failure) were incorporated into the Cox model as time-dependent covariates.

The data set that was extracted consisted of yearly summaries (medians) of SAA values for each patient (e.g., the median SAA value for year 1 was calculated as the median value of all the measurements obtained during the first year of follow-up), and these values were updated in the Cox model at yearly intervals. Changes in the amyloid burden were assessed annually and updated in the model at each annual follow-up assessment, along with renal-function status and serum albumin concentration; end-stage renal failure was incorporated in the model as a binary variable with a value of 0 before the onset of end-stage renal failure and of 1 thereafter. Continuous measurements were categorized into octiles, and unadjusted relative risks were examined to assess whether it was appropriate to simplify the models by including each measurement in the model as a continuous covariate (possibly after log transformation). Variables that were significant in the univariate models $(\mathrm{P}<0.01)$ were analyzed in a multivariate regression model with the use of a backward-selection procedure and SAS software, version 9.1.

RESULTS

\section{BASELINE CHARACTERISTICS}

Baseline characteristics of the 374 patients are listed in Table 2. The most frequent underlying disorder was inflammatory arthritis (Table 1). Rare causes of AA amyloidosis included vasculitis, sickle cell anemia, malignant disease, epidermolysis bullosa, and cyclic neutropenia. For 23 patients, the precise nature of the inflammatory disorder could not be established, despite extensive investigation. The median duration of symptomatic inflammatory disease before the diagnosis of amyloidosis was 17 years, and there were no significant differences in latency among the various underlying disorders.

The predominant feature of amyloidosis at diagnosis was renal dysfunction; in $97 \%$ of patients, more than $500 \mathrm{mg}$ of protein per day was excreted or the serum creatinine concentration was more than $1.5 \mathrm{mg}$ per deciliter (133 $\mu \mathrm{mol}$ per liter), or both; at diagnosis, 41 patients (11\%) had end-stage renal failure. Median protein excretion among the 333 patients not requiring dialysis was $3.9 \mathrm{~g}$ per day (interquartile range, 1.9 to 6.3); of these patients, $12 \%$ had urinary protein excretion of more than $10 \mathrm{~g}$ per day, and $2 \%$ had urinary protein excretion of more than $20 \mathrm{~g}$ per day; the serum albumin concentration was less than $3.5 \mathrm{~g}$ per deciliter in 184 patients (55\%). Among those not requiring dialysis, the median serum creatinine concentration at baseline was $1.2 \mathrm{mg}$ per deciliter (interquartile range, 0.8 to 2.4$)(106 \mu \mathrm{mol}$ per liter [interquartile range, 71 to 212]); the serum creatinine concentration was less than $3.0 \mathrm{mg}$ per deciliter (265 $\mu \mathrm{mol}$ per liter) at diagnosis in $75 \%$ of patients.

Hepatomegaly was present on examination at baseline in 35 patients (9\%), but hepatic amyloid deposits were evident on SAP scintigraphy in 85 patients (23\%). Serum alkaline phosphatase concentrations greater than 1.5 times the upper limit of the normal range (which varies according to age, sex, and method of analysis), a value that is widely regarded as suggesting liver involvement in amyloidosis, ${ }^{17}$ were present in 21 patients with hepatic amyloidosis but also in 25 patients who had normal liver signal on SAP scintigraphy. The median SAA concentration in these patients was 


\begin{tabular}{|c|c|c|}
\hline Characteristic & $\begin{array}{l}\text { All Patients } \\
(\mathrm{N}=374)\end{array}$ & $\begin{array}{l}\text { Patients with Creatinine } \\
\text { Clearance }>20 \mathrm{ml} / \mathrm{min} \\
\qquad(\mathrm{N}=257)\end{array}$ \\
\hline Male sex 一 no. (\%) & $210(56)$ & $140(54)$ \\
\hline \multicolumn{3}{|l|}{ Race or ethnic group — no. (\%) $\dagger$} \\
\hline White & $307(82)$ & $214(83)$ \\
\hline South Asian & $27(7)$ & $17(7)$ \\
\hline Other & $40(11)$ & $26(10)$ \\
\hline \multicolumn{3}{|l|}{ Age at diagnosis $-\mathrm{yr}$} \\
\hline Median & 50 & 47 \\
\hline Range & $9-87$ & $9-78$ \\
\hline \multicolumn{3}{|l|}{ Duration of inflammatory disease at diagnosis - yr } \\
\hline Median & 17 & 18 \\
\hline Range & $0-68$ & $2-68$ \\
\hline \multicolumn{3}{|l|}{ Amyloid load on SAP scintigraphy — no. (\%) } \\
\hline Small & $96(26)$ & $71(28)$ \\
\hline Moderate & $213(57)$ & $144(56)$ \\
\hline Large & $63(17)$ & $42(16)$ \\
\hline Hepatic amyloid deposits at baseline - no. (\%) & $85(23)$ & $54(21)$ \\
\hline \multicolumn{3}{|l|}{ End-stage renal failure — no. (\%) } \\
\hline Present at baseline & $41(11)$ & NA \\
\hline Developed during follow-up & $110(33)$ & $59(23)$ \\
\hline Death during follow-up & $163(44)$ & $101(39)$ \\
\hline \multicolumn{3}{|l|}{ Baseline laboratory values } \\
\hline \multicolumn{3}{|l|}{$\mathrm{SAA}-\mathrm{mg} / \mathrm{liter}$} \\
\hline Median & 28 & 26.5 \\
\hline Range & $0.7-1610$ & $0.7-1610$ \\
\hline \multicolumn{3}{|l|}{ C-reactive protein $-\mathrm{mg} /$ liter } \\
\hline Median & 20 & 17 \\
\hline Range & $0.7-206$ & $0.7-187$ \\
\hline \multicolumn{3}{|l|}{ Serum creatinine $-\mathrm{mg} / \mathrm{dl}$} \\
\hline Median & 1.78 & 1.12 \\
\hline Range & $0.37-13.9$ & $0.37-3.32$ \\
\hline \multicolumn{3}{|l|}{ Creatinine clearance $-\mathrm{ml} / \mathrm{min}$} \\
\hline Median & 41 & 63 \\
\hline Range & $0-186$ & $20-186$ \\
\hline \multicolumn{3}{|l|}{ Proteinuria - g of protein/day } \\
\hline Median & 3.9 & 3.6 \\
\hline Range & $0-26.0$ & $0-21$ \\
\hline \multicolumn{3}{|l|}{ Albumin $-\mathrm{g} / \mathrm{dl}$} \\
\hline Median & 3.0 & 3.0 \\
\hline Range & $0.8-4.9$ & $0.8-4.9$ \\
\hline
\end{tabular}

* To convert the values for creatinine to millimoles per liter, multiply by 88.4. To convert the values for creatinine clearance to milliliters per second, multiply by 0.01667 . SAP denotes serum amyloid P component, and NA not applicable. $\dagger$ Race or ethnic group was self-reported. 


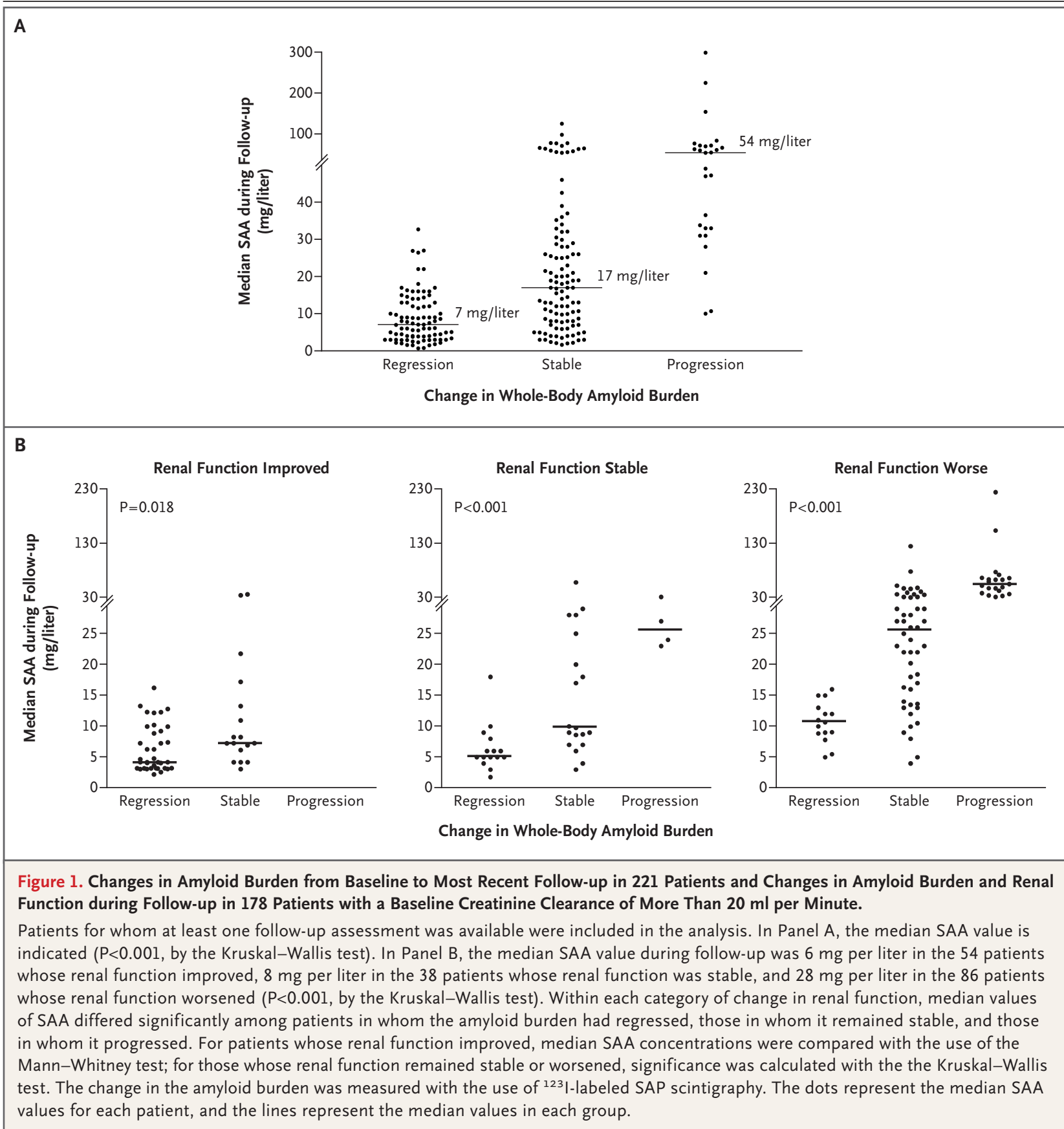

$51 \mathrm{mg}$ per liter, a finding that is consistent with increased production of alkaline phosphatase as an acute-phase reactant. No patient had jaundice, elevated serum aminotransferase concentrations, or hepatic synthetic dysfunction.

Cardiac failure attributable to amyloidosis was present in only 1 patient, and findings consistent with cardiac infiltration were present in only 2 of
224 patients who underwent echocardiography. No patient had symptomatic autonomic neuropathy, and although adrenal amyloid deposits were evident on SAP scintigraphy in $41 \%$ of the patients, only five required long-term adrenocorticoid replacement therapy.

SAP scintigraphy was diagnostic of amyloidosis at baseline in all but four patients, each of whom 
had nonfunctioning atrophic kidneys and had undergone splenectomy. In 370 patients (99\%), the scans showed striking splenic amyloid deposits, and in 331 patients (89\%), the scans also showed renal or adrenal deposits, or both.

\section{CLINICAL COURSE AND OUTCOME}

The cohort was followed for a median of 86 months (range, 2 to 447) after diagnosis, representing 2673 person-years. Forty-seven patients (13\%) were lost to follow-up, and data for them were censored as of the date of the last contact. A total of 221 patients underwent serial SAP scintigraphy; in 27 (12\%) the amyloid burden increased, in 107 (48\%) it was unchanged, and in 87 (39\%) there was evidence of regression from baseline to the most recent followup assessment (Fig. 1 and 2). SAA values were significantly lower in patients in whom amyloid deposits regressed (median, $7 \mathrm{mg}$ per liter) than in those in whom the amyloid burden increased (median, $54 \mathrm{mg}$ per liter) $(\mathrm{P}<0.001)$.

A total of 163 patients (44\%) died, and the median survival from diagnosis was 133 months (95\% confidence interval [CI], 100 to 153) in the Kaplan-Meier analysis. The median SAA concentration during each year of follow-up was strongly associated with survival (Table 3); the relative risk of death among patients with an SAA concentration of less than $4 \mathrm{mg}$ per liter (the lowest octile) was almost 18 times lower than among patients with an SAA concentration of $155 \mathrm{mg}$ per liter or greater (the highest octile). Even among those in the second-lowest octile, the very modest elevation in the SAA concentration of 4 to $9 \mathrm{mg}$ per liter, which is widely cited as within the normal reference range, was associated with a risk of death that was increased by a factor of 4 , as compared with those with SAA concentrations in the lowest octile.

Other factors associated with increased mortality were older age (relative risk of death, 1.53 for each additional decade of age [95\% CI, 1.34 to 1.74]; $\mathrm{P}<0.001)$ and end-stage renal failure (relative risk, 2.97 [95\% CI, 2.10 to 4.21]; $\mathrm{P}<0.001$ ) (Table 4). In contrast, underlying periodic fever syndromes and evidence of regression of amyloid on serial SAP scintigraphy were both associated with reduced mortality (relative risk of death, 0.36 [95\% CI, 0.14 to $0.88 ; \mathrm{P}=0.03$ ] and 0.13 [95\% CI, 0.02 to 0.94; $\mathrm{P}=0.04$ ], respectively) (Table 4).

Among the 257 patients who had a creatinine clearance greater than $20 \mathrm{ml}$ per minute at base- line, 59 (23\%) had progression to end-stage renal failure; the estimated median time to end-stage renal failure from diagnosis was 256 months in the Kaplan-Meier analysis. The relative risk of endstage renal failure was 1.24 (95\% CI, 1.08 to 1.43; $\mathrm{P}=0.002$ ) for each doubling of the SAA concentration. Among 178 patients for whom at least one

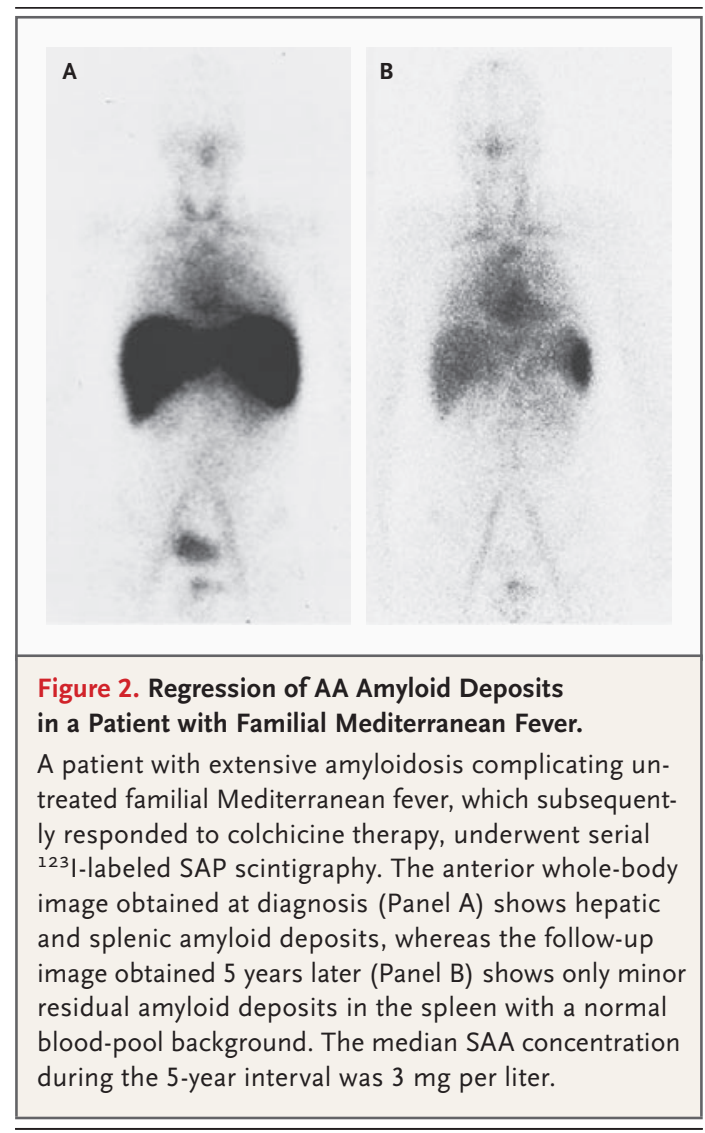

Table 3. Unadjusted Relative Risk of Death Associated with the Most Recent Median Annual SAA Concentration during Follow-up.*

$\begin{array}{ccc}\text { SAA Octile }(\mathrm{mg} / \text { liter }) & \text { Relative Risk }(95 \% \mathrm{CI}) & \text { P Value } \\ <4 & 1.0 & \\ \geq 4 \text { to }<9 & 3.9(1.5-10.4) & 0.007 \\ \geq 9 \text { to }<16.7 & 5.1(2.7-9.4) & 0.003 \\ \geq 16.7 \text { to }<28 & 7.0(3.7-13.4) & 0.07 \\ \geq 28 \text { to }<45.6 & 9.1(4.8-17.2) & 0.008 \\ \geq 45.6 \text { to }<87 & 12.1(6.9-21.4) & <0.001 \\ \geq 87 \text { to }<155 & 17.0(8.6-33.8) & <0.001 \\ \geq 155 & 17.7(8.7-36.0) & <0.001\end{array}$

* The SAA value is the median concentration within each 12-month period and was incorporated into the Cox regression model as a time-dependent covariate. 


\begin{tabular}{|c|c|c|c|c|}
\hline Factor & $\begin{array}{l}\text { Unadjusted Relative Risk } \\
\qquad(95 \% \mathrm{Cl}) \dagger\end{array}$ & P Value & $\begin{array}{c}\text { Adjusted Relative Risk } \\
(95 \% \mathrm{Cl}) \div\end{array}$ & P Value \\
\hline \multicolumn{5}{|l|}{ Associated with death } \\
\hline \multicolumn{5}{|l|}{ Factors at baseline } \\
\hline Age (per additional decade of age) & $1.62(1.45-1.81)$ & $<0.001$ & $1.53(1.34-1.74)$ & $<0.001$ \\
\hline White race & $2.03(1.18-3.52)$ & 0.01 & & \\
\hline \multicolumn{5}{|l|}{ Underlying disease } \\
\hline Rheumatoid arthritis & 1.00 & & & \\
\hline Juvenile idiopathic arthritis & $0.23(0.14-0.38)$ & $<0.001$ & & \\
\hline Periodic fever syndromes & $0.21(0.09-0.49)$ & $<0.001$ & $0.36(0.14-0.88)$ & 0.03 \\
\hline Crohn's disease & $0.31(0.11-0.85)$ & 0.02 & & \\
\hline Undetermined disease & $0.27(0.10-0.73)$ & 0.01 & & \\
\hline \multicolumn{5}{|l|}{ Amyloid burden on SAP scintigraphy } \\
\hline Small & 1.00 & & & \\
\hline Moderate & $1.55(1.04-2.33)$ & 0.03 & & \\
\hline Large & $1.99(1.22-3.25)$ & 0.006 & & \\
\hline Duration of inflammatory disease (per 5-yr interval) & $1.09(102-1.17)$ & 0.01 & & \\
\hline \multicolumn{5}{|l|}{ Factors that could change during follow-up } \\
\hline Serum albumin $(\geq 0.5 \mathrm{~g} / \mathrm{dl})$ & $0.78(0.72-0.86)$ & $<0.001$ & & \\
\hline SAA (by a factor $\geq 2$ ) & $1.39(1.28-1.51)$ & $<0.001$ & $1.27(1.16-1.40)$ & $<0.001$ \\
\hline Serum creatinine (by a factor $\geq 2$ ) & $1.44(1.26-1.64)$ & $<0.001$ & & \\
\hline Creatinine clearance $(\geq 5 \mathrm{ml} / \mathrm{min})$ & $0.95(0.93-0.97)$ & $<0.001$ & & \\
\hline End-stage renal failure & $2.85(2.10-3.89)$ & $<0.001$ & $2.97(2.10-4.21)$ & $<0.001$ \\
\hline \multicolumn{5}{|l|}{ Change in amyloid deposits } \\
\hline Progressed & $1.41(0.91-2.18)$ & 0.13 & & \\
\hline Stable & 1.00 & & & \\
\hline Regressed & $0.15(0.08-0.32)$ & $<0.001$ & $0.13(0.02-0.94)$ & 0.04 \\
\hline
\end{tabular}

assessment during follow-up was available, renal function improved in 54 patients and deteriorated in 86 patients, and improvement was associated with median SAA values of $6 \mathrm{mg}$ per liter and 28 mg per liter, respectively ( $\mathrm{P}<0.001$ by the KruskalWallis test) (Fig. 1). Among the 92 patients in whom values for creatinine clearance remained stable or improved, the nephrotic syndrome abated in 33 patients after a median of 29 months, as defined by the disappearance of edema, a decrease in urinary protein excretion to less than $3 \mathrm{~g}$ per day, and an increase in the serum albumin concentration to $3.5 \mathrm{~g}$ per deciliter or more.

Cox regression analyses (Table 4) indicated that the relative risk of progression to end-stage renal failure was four times as high among patients who had underlying Crohn's disease or chronic sepsis as among those who did not $(\mathrm{P}=0.01$ and $\mathrm{P}=0.006$, respectively) and two times as high among patients who had hepatic amyloid deposits at baseline as among those who did not $(\mathrm{P}=0.04)$. The relative risk of progression to end-stage renal failure was also increased among patients whose renal function was relatively worse at baseline, with an increase by a factor of 5 for each doubling of the baseline serum creatinine concentration $(\mathrm{P}<0.001)$.

Five patients had a very rapid and striking relapse of proteinuric renal dysfunction when there was a flare of inflammatory disease activity during follow-up. For example, the amyloid-related nephrotic syndrome resolved gradually over a period of 4 years in a patient whose underlying rheuma- 


\begin{tabular}{|c|c|c|c|c|}
\hline Factor & $\begin{array}{l}\text { Unadjusted Relative Risk } \\
\qquad(95 \% \mathrm{Cl}) \dagger\end{array}$ & P Value & $\begin{array}{c}\text { Adjusted Relative Risk } \\
(95 \% \mathrm{Cl}) \doteqdot\end{array}$ & P Value \\
\hline \multicolumn{5}{|l|}{ Associated with progression to end-stage renal failure } \\
\hline \multicolumn{5}{|l|}{ Factors at baseline } \\
\hline \multicolumn{5}{|l|}{ Underlying disease } \\
\hline Rheumatoid arthritis & 1.00 & & & \\
\hline Juvenile idiopathic arthritis & $0.43(0.19-0.98)$ & 0.04 & & \\
\hline Chronic sepsis & $2.38(0.96-5.91)$ & 0.06 & $4.01(1.49-0.78)$ & 0.006 \\
\hline Crohn's disease & $5.48(1.94-5.48)$ & 0.001 & $4.14(1.32-2.95)$ & 0.01 \\
\hline \multicolumn{5}{|l|}{ Amyloid burden } \\
\hline Small & 1.00 & & & \\
\hline Moderate & $2.08(1.06-4.11)$ & 0.03 & & \\
\hline Large & $2.71(1.15-6.37)$ & 0.02 & & \\
\hline Hepatic amyloid deposits & $1.75(0.97-3.17)$ & 0.06 & $1.98(1.02-3.82)$ & 0.04 \\
\hline Duration of inflammatory disease (per 5-yr interval) & $1.15(1.02-1.30)$ & 0.03 & & \\
\hline Serum creatinine (by a factor $\geq 2$ ) & $2.31(1.67-3.20)$ & $<0.001$ & $5.04(2.47-10.30)$ & $<0.001$ \\
\hline \multicolumn{5}{|l|}{ Factors that could change during follow-up } \\
\hline Serum albumin $(\geq 0.5 \mathrm{~g} / \mathrm{dl})$ & $0.74(0.64-0.86)$ & $<0.001$ & $0.82(0.70-0.96)$ & 0.01 \\
\hline SAA (by a factor $\geq 2$ ) & $1.32(1.16-1.50)$ & $<0.001$ & $1.24(1.08-1.43)$ & 0.002 \\
\hline \multicolumn{5}{|l|}{ Change in amyloid deposits } \\
\hline Progressed & $3.14(1.67-5.90)$ & $<0.001$ & & \\
\hline Stable & 1.00 & & & \\
\hline Regressed & $0.46(0.21-1.02)$ & 0.06 & & \\
\hline
\end{tabular}

toid arthritis was in sustained complete remission, yet when an intense acute-phase reaction associated with community-acquired pneumonia developed in this patient, the nephrotic syndrome recurred within 2 weeks. Her renal function normalized again during the ensuing 2 years.

\section{DISCUSSION}

This study involving patients with AA amyloidosis included specific quantitative measurements of the whole-body amyloid burden on SAP scintigraphy and the circulating AA amyloid fibril precursor SAA. Observations that challenge the still widespread perception of amyloidosis as an inexorably progressive disease include the demon- stration that AA amyloid deposits often regress and that survival is prolonged in patients in whom the circulating SAA concentration remains at low values.

Although the spleen, adrenal glands, liver, and gut are frequent sites of AA amyloid deposition, renal involvement dominated the clinical course in the patients in this study. Evidence of amyloid cardiomyopathy and autonomic neuropathy were extremely rare, as compared with previously reported series. ${ }^{20,21}$ None of the patients had clinically significant liver amyloidosis; furthermore, nearly one third of the patients with an elevated serum alkaline phosphatase concentration, which has been suggested as a marker of hepatic amyloid by an international consensus panel, ${ }^{17}$ had no evidence 
of liver deposits on SAP scintigraphy. The features of amyloidosis in terms of the duration of underlying disease, clinical presentation, distribution of amyloid deposits, and outcome were similar in patients with different types of underlying inflammatory disorders, with the exception of a worse renal outcome in patients with chronic sepsis or Crohn's disease. It is possible that the high frequency of surgical intervention and administration of immunosuppressive drugs contributed to renal failure in patients with Crohn's disease.

Factors associated with a poor prognosis included older age, a reduced serum albumin concentration, end-stage renal failure at baseline, and the degree by which the SAA concentration was elevated during follow-up. Increased production of SAA was the most powerful risk factor for endstage renal failure and death, but it is also one that may be ameliorated through antiinflammatory treatment.

Despite the high correlations among SAA production, amyloid burden, and renal function overall within the cohort, the association between the median SAA concentration and the status of the amyloid deposits did differ among individual patients (Fig. 1). Thus, although amyloid deposits regressed in about $60 \%$ of patients whose median SAA concentration was less than $10 \mathrm{mg}$ per liter, the deposits were stable in the remainder. Similarly, although the amyloid deposits progressed in all patients whose median SAA concentration was more than $120 \mathrm{mg}$ per liter, deposits among individual patients with moderately elevated SAA concentrations were stable, regressed, or progressed. The efficiency with which SAA is converted into amyloid or the rate at which amyloid deposits are turned over within the tissues, or both, may differ from patient to patient, although neither mechanism has been elucidated.

There were also differences between individual patients in the relationship between amyloid burden and renal function. Renal function improved in 17 patients in whom the amyloid burden was merely stable, and it deteriorated in 15 patients in whom amyloid deposits regressed. The basis for renal recovery in association with a stable amyloid burden and a low SAA concentration is unknown. However, progressive kidney dysfunction in patients in whom the amyloid deposits regressed was undoubtedly influenced by additional renal insults, including drugs, sepsis, hypovolemia, and hypertension, as well as by the extent of irreversible re- nal damage occurring before diagnosis. Discrepancies between the course of the amyloid deposits and the direction of change in organ function are salient reminders that the molecular mechanisms of tissue damage in amyloidosis actually remain little understood.

In contrast to the improvement in amyloidassociated renal dysfunction after successful antiinflammatory therapy that typically took months to years, the relapse of renal dysfunction after renewed inflammatory disease activity could be remarkably rapid. This finding probably reflects the conversion of abundant SAA into its fibrillar form on a template of residual amyloid deposits. This finding is reminiscent of the long-recognized phenomenon of the "amyloid-enhancing factor" that has been observed in experimentally induced murine AA amyloidosis, in which substantial amyloid deposits can develop in less than 24 hours in mice injected with ex vivo amyloid material and subsequently given an inflammatory stimulus. ${ }^{22,23}$

Treatment of AA amyloidosis depends on control of the underlying inflammatory disorder. Successful pharmacologic approaches in our patients ranged from nonspecific immunosuppression for those with inflammatory arthritis treated with chlorambucil ${ }^{24}$ to highly specific inhibition of interleukin-1 for those with the Muckle-Wells syndrome (an autosomal dominant fever syndrome characterized by urticaria, progressive perceptive deafness, and amyloidosis). ${ }^{25}$ Surgical treatments included excision of solitary cytokine-secreting Castleman's tumors (angiofollicular lymph-node hyperplasia ${ }^{26}$ and amputation of osteomyelitic limbs. Surprisingly, 23 patients (6\%) who presented with AA amyloidosis had clinically covert inflammatory disease that could not be characterized. The majority of these patients had been presumed by their referring physicians to have primary AL amyloidosis, yet on immunohistochemical testing, we confirmed AA amyloid in all of them. Antiinflammatory treatment must be empirical in such patients but should be guided, we believe, as in all patients with AA amyloidosis, by frequent measurement of SAA concentrations. ${ }^{27}$

In conclusion, AA amyloidosis usually presents with proteinuric renal dysfunction, for which patients with chronic inflammatory disorders should be evaluated routinely. The period of latency between the onset of inflammation and clinical presentation with AA amyloidosis appears to vary and is often prolonged, but the progression of 
amyloid can be rapid. In the present study, decreased production of SAA was associated with a favorable renal outcome, stabilization or regression of amyloid deposits, and prolonged survival.

Supported in part by grants from the U.K. Medical Research Council (G7900510, to Dr. Hawkins) and the National Health Service. Dade Behring provided the BN II analyzer and SAA assay kits.
Dr. Lachmann reports receiving consulting fees from Neurochem and Genzyme, and Dr. Hawkins, consulting fees from Domantis. No other potential conflict of interest relevant to this article was reported.

We thank our many colleagues for referring and caring for the patients; S. Madhoo, P. Spencer-Gittens, and D. Gopaul for their care of the patients at the National Amyloidosis Centre; and M. Pepys at the National Amyloidosis Centre for his scientific support, review of the manuscript, and establishment of the National Amyloidosis Centre.

\section{REFERENCES}

1. Merlini G, Bellotti V. Molecular mechanisms of amyloidosis. N Engl J Med 2003; 349:583-96.

2. Pepys MB. Amyloidosis. Annu Rev Med 2006;57:223-41.

3. Parmelee DC, Titani K, Ericsson LH, Eriksen N, Benditt EP, Walsh KA. Amino acid sequence of amyloid-related apoprotein $\left(\right.$ apoSAA $_{1}$ ) from human high density lipoprotein. Biochemistry 1982;21:3298-303.

4. Urieli-Shoval S, Linke RP, Matzner Y. Expression and function of serum amyloid A, a major acute-phase protein, in normal and disease states. Curr Opin Hematol 2000;7:64-9.

5. Ledue TB, Weiner DL, Sipe JD, Poulin SE, Collins MF, Rifai N. Analytical evaluation of particle-enhanced immunonephelometric assays for C-reactive protein, serum amyloid $\mathrm{A}$ and mannose-binding protein in human serum. Ann Clin Biochem 1998;35:745-53.

6. Laiho K, Tiitinen S, Kaarela K, Helin $\mathrm{H}$, Isomaki $\mathrm{H}$. Secondary amyloidosis has decreased in patients with inflammatory joint disease in Finland. Clin Rheumatol 1999;18:122-3.

7. Singh G, Kumari N, Aggarwal A, Krishnani N, Misra R. Prevalence of subclinical amyloidosis in ankylosing spondylitis. J Rheumatol 2007;34:371-3.

8. Lachmann HJ, Booth DR, Booth SE, et al. Misdiagnosis of hereditary amyloidosis as AL (primary) amyloidosis. $\mathrm{N}$ Engl J Med 2002;346:1786-91.

9. Benson MD. Ostertag revisited: the in herited systemic amyloidoses without neuropathy. Amyloid 2005;12:75-87.

10. Lachmann HJ, Gallimore R, Gillmore $\mathrm{JD}$, et al. Outcome in systemic AL amyloidosis in relation to changes in concentration of circulating free immunoglobulin light chains following chemotherapy. $\mathrm{Br}$ J Haematol 2003;122:78-84.

11. Rajkumar SV, Dispenzieri A, Kyle RA.
Monoclonal gammopathy of undetermined significance, Waldenstrom macroglobulinemia, AL amyloidosis, and related plasma cell disorders: diagnosis and treatment. Mayo Clin Proc 2006;81:693-703. [Erratum, Mayo Clin Proc 2006;81:1509.] 12. Puchtler H, Sweat F, Levine M. On the binding of Congo red by amyloid. J Histochem Cytochem 1962;10:355-64.

13. Hazenberg BPC, Grond J, van den Top D, Bijzet J, Limburg PC, van Rijswijk MH. Immunohistochemical detection of amyloid AA in formaline-fixed paraffin-embedded rectal biopsies with the monoclonal anti-human SAA antibody Reu.86.2. In: Natvig JB, Forre O, Husby G, et al., eds. Amyloid and amyloidosis 1990. Dordrecht, the Netherlands: Kluwer Academic, 1991: 809-12.

14. Hawkins PN, Lavender JP, Pepys MB. Evaluation of systemic amyloidosis by scintigraphy with ${ }^{123}$ I-labeled serum amyloid P component. N Engl J Med 1990;323: 508-13.

15. Hawkins PN, Richardson S, MacSweeney JE, et al. Scintigraphic quantification and serial monitoring of human visceral amyloid deposits provide evidence for turnover and regression. Q J Med 1993;86:36574.

16. Rydh A, Suhr O, Hietala S-O, Åhlström KR, Pepys MB, Hawkins PN. Serum amyloid $\mathrm{P}$ component scintigraphy in familial amyloid polyneuropathy: regression of visceral amyloid following liver transplantation. Eur J Nucl Med 1998;25:709-13.

17. Gertz MA, Comenzo R, Falk RH, et al. Definition of organ involvement and treatment response in immunoglobulin light chain amyloidosis (AL): a consensus opinion from the 10th International Symposium on Amyloid and Amyloidosis, Tours, France, 18-22 April 2004. Am J Hematol 2005;79:319-28.

18. WHO Expert Committee on Biological
Standardization: 48th report. World Health Organ Tech Rep Ser 1999;889:18-9.

19. Poole S, Walker D, Gaines Das RE, Gallimore JR, Pepys MB. The first international standard for serum amyloid A protein (SAA): evaluation in an international collaborative study. J Immunol Methods 1998;214:1-10.

20. Tanaka K, Horita M, Shibayama H, et al. Secondary amyloidosis associated with Castleman's disease. Intern Med 1995;34: 122-6.

21. Hamer JPM, Janssen S, van Rijswijk $\mathrm{MH}$, Lie KI. Amyloid cardiomyopathy in systemic non-hereditary amyloidosis: clinical, echocardiographic and electrocardiographic findings in 30 patients with AA and 24 patients with AL amyloidosis. Eur Heart J 1992;13:623-7.

22. Werdelin O, Ranlov P. Amyloidosis in mice produced by transplantation of spleen cells from casein-treated mice. Acta Pathol Microbiol Scand 1966;68:1-18.

23. Kisilevsky R, Gruys E, Shirahama T. Does amyloid enhancing factor (AEF) exist? Is AEF a single biological entity? Amyloid: Int J Exp Clin Invest 1995;2:128-33.

24. Schnitzer TJ, Ansell BM. Amyloidosis in juvenile chronic polyarthritis. Arthritis Rheum 1977;20:Suppl 2:245-52.

25. Hawkins PN, Lachmann HJ, McDermott MF. Interleukin-1-receptor antagonist in the Muckle-Wells syndrome. N Engl J Med 2003;348:2583-4.

26. Shimojima Y, Takei $Y$, Tazawa K, et al. Histopathological regression of systemic AA amyloidosis after surgical treatment of a localized Castleman's disease. Amyloid 2006;13:184-6.

27. Gillmore JD, Lovat LB, Persey MR, Pepys MB, Hawkins PN. Amyloid load and clinical outcome in AA amyloidosis in relation to circulating concentration of serum amyloid A protein. Lancet 2001;358:24-9.

Copyright $\odot 2007$ Massachusetts Medical Society.

POSTING PRESENTATIONS AT MEDICAL MEETINGS ON THE INTERNET

Posting an audio recording of an oral presentation at a medical meeting on the Internet, with selected slides from the presentation, will not be considered prior publication. This will allow students and physicians who are unable to attend the meeting to hear the presentation and view the slides. If there are any questions about this policy, authors should feel free to call the Journal's Editorial Offices. 